Keiko Fujiki • Kiyoo Nakayasu • Atsushi Kanai

\section{Corneal dystrophies in Japan}

Received: March 1, 2001 / Accepted: April 21, 2001

\begin{abstract}
Recent advances in molecular genetics have increased our understanding of the role of genes. Four autosomal dominant corneal dystrophies (CDs); granular CD (GCD), Avellino CD (ACD), lattice CD (LCD), and ReisBücklers CD (RBCD) were mapped to the long arm of chromosome 5 (5q31). These four diseases were shown, in a Caucasian series, to result from different missense mutations in the TGFBI (BIGH3, keratoepithelin) gene. The same mutations were also detected in Japanese patients, from a different ethnic background. Gelatinous drop-like corneal dystrophy (GDLD), on the other hand, which was found in Japanese patients in 1914, is a rare autosomal recessive disorder characterized by corneal amyloidosis. Parents of the patients had a markedly higher frequency of consanguineous marriages than the general population. The gene responsible for GDLD, the membrane component, chromosome 1, surface marker 1 (M1S1) gene was mapped to the short arm of chromosome 1(1p). Four deleterious mutations in this gene were detected in Japanese patients. We review here additional studies on mutations of the TGFBI and M1S1 genes found in Japanese patients. In the $T G F B I$ gene, nine different mutations were detected in Japanese patients with GCD, ACD, LCD, or RBCD. The codons R124 and R555 of the TGFBI gene were hotspots in Japanese patients, of whom many were ACD patients with the R124H mutation. New mutations responsible for LCD were detected in the $T G F B I$ gene of patients with LCD, in addition to the P501T mutation in LCD type IIIA found earlier. These studies showed a clear genotype/phenotype correlation associated with the TGFBI gene. In the M1S1 gene, the Q118X mutation was the most common alteration, and a founder mutation in Japanese GDLD patients, as previously reported. Ninety-two percent of the mutated alleles were the Q118X.
\end{abstract}

K. Fujiki $(\bowtie) \cdot$ K. Nakayasu $\cdot$ A. Kanai

Department of Ophthalmology, Juntendo University School of

Medicine, 3-1-3 Hongo, Bunkyo-ku, Tokyo 113-8431, Japan

Tel. +81-3-5802-1092; Fax +81-3-3817-0260

e-mail: fujiki@med.juntendo.ac.jp
Key words Hereditary corneal dystrophy • TGFBI (BIGH3) gene - M1S1 gene - Mutation - Founder mutation · Avellino corneal dystrophy · Gelatinous drop-like corneal dystrophy

\section{Introduction}

Corneal dystrophies (CDs) are inherited, bilateral, primary alterations of the cornea that are not associated with prior inflammation or systemic diseases. Recent advances in molecular genetics have revealed the genes responsible for many corneal dystrophies (Table 1). Three types of autosomal dominant CDs were mapped to the long arm of human chromosome 5 (5q31) (Stone et al. 1994). These are granular Groenouw type I (GCDGI), Avellino CD (ACD), and lattice CD type I (LCDI). In addition, Reis-Bücklers CD (RBCD) was also mapped to the same locus (Small et al. 1996). These four CDs show clinically progressive opacities of the cornea, leading to severe visual impairment. In 1997, missense mutations in the transforming growth factor beta-induced (TGFBI, BIGH3) gene encoding keratoepithelin were identified in these four CDs in patients of Caucasian background (Munier et al. 1997). The same mutations were also detected in patients from a different ethnic background i.e., Japanese patients (Mashima et al. 1997; Konishi et al. 1998 and 1999; Fujiki et al. 1998a; Okada et al. 1998a; Hotta et al. 1998). Moreover, new mutations in the same gene were reported in Japanese patients (Yamamoto et al. 1998; Fujiki et al. 1998b; Okada et al. 1998b; Endo et al. 1999).

Gelatinous drop-like corneal dystrophy (GDLD), which was detected in Japanese patients by Nakaizumi (1914), is, on the other hand, an autosomal recessive disorder characterized by clinically grayish corneal amyloid deposits that cause severe visual impairment. The prevalence rate was calculated to be $1 / 33,000$ in a nationwide survey of patients and frequencies of consanguineous marriages (Kawano et al. 1992). The disorder was observed mostly in the offspring of consanguineous marriages, with the parents of the 
Table 1. Mode of inheritance, gene loci, and genes cloned in herditary corneal dystrophy

\begin{tabular}{|c|c|c|c|c|}
\hline Corneal layer & Disease & Inheritance & Gene locus & Gene \\
\hline Epithelium & Meesmann's dystrophy & $\begin{array}{l}\mathrm{AD} \\
\mathrm{AD}\end{array}$ & $\begin{array}{l}12 \mathrm{q} 13 \\
17 \mathrm{q} 12-\mathrm{q} 21\end{array}$ & $\begin{array}{l}\text { KRT3 } \\
\text { KRT12 }\end{array}$ \\
\hline Stroma & \begin{tabular}{l} 
Reis-Bücklers CD \\
Granular CD (Groenouw I) \\
Avellino CD \\
Lattice CD $\quad$ Type I \\
\\
\multicolumn{1}{c}{ Type IIIA } \\
Type IV \\
Type II \\
Gelatinous drop-like CD \\
Macular CD type I, type II \\
Schnyder's crystalline dystrophy
\end{tabular} & $\begin{array}{l}\mathrm{AD} \\
\mathrm{AD} \\
\mathrm{AR} \\
\mathrm{AR} \\
\mathrm{AD}\end{array}$ & $\begin{array}{l}5 q 31 \\
\\
9 q 34 \\
1 p 32-q 12 \\
16 q 22 \\
1 p 36-p 34.1\end{array}$ & $\begin{array}{l}\text { TGFBI } \\
\text { GSN } \\
\text { M1S1 } \\
\text { CHST6 }\end{array}$ \\
\hline Endothelium & $\begin{array}{l}\text { Fuchs' endothelial dystrophy } \\
\text { Posterior polymorphous dystrophy (PPD) }\end{array}$ & $\begin{array}{l}\mathrm{AD} \\
\mathrm{AD}\end{array}$ & $\overline{20 \mathrm{q} 11}$ & \\
\hline & $\begin{array}{l}\text { Congenital hereditary } \\
\text { endothelial dystrophy (CHED) } \\
\text { (CHED 2) }\end{array}$ & $\begin{array}{l}\mathrm{AD} \\
\mathrm{AR}\end{array}$ & $\begin{array}{l}20 \\
20\end{array}$ & \\
\hline
\end{tabular}

$\mathrm{AD}$, autosomal dominant; $\mathrm{AR}$, autosomal recessive; $\mathrm{CD}$, corneal dystrophy

probands showing a frequency of $43 \%$ of consanguineous marriages, higher than that in the general population, which was $6.8 \%$ in the marriage year of parents of the probands. It is interesting that the incidence of recessive disorders (Saito 1985 and 1988; Hayakawa et al. 1997), including GDLD (Kawano et al. 1992), has decreased in Japan, because of the marked decrease in consanguineous marriages in recent years in the Japanese population (Imaizumi 1986; Hosoda et al. 1983). The gene responsible for GDLD was mapped to the short arm of chromosome 1 (1p) (Tsujikawa et al. 1998). The membrane component, chromosome 1 , surface marker 1 (M1S1) gene, the gene responsible for GDLD, was cloned, and four deleterious mutations were detected in this gene in Japanese patients (Tsujikawa et al. 1999).

We present here the findings of our own studies and cite recent advances in findings about two kinds of CDs in Japanese patients. The first is an autosomal dominant CD affected by alterations in the TGFBI gene, and includes Avellino CD (ACD), granular CD (GCD), lattice CD (LCD), and Reis-Bücklers CD (RBCD). The second is an autosomal recessive $\mathrm{CD}$, gelatinous drop-like corneal dystrophy (GDLD), which is associated with alterations in the M1S1 gene.

\section{Materials and methods}

In our studies, we analyzed findings in 121 families, including 158 patients and 41 unaffected relatives of patients manifesting GCD, LCD, or RBCD; and 8 families, including 10 patients and 18 unaffected relatives, manifesting the autosomal recessive GDLD. Fifty normal volunteers served as controls. All studies were performed according to the guidelines of the Declaration of Helsinki. Appropriate informed consent was obtained from each subject before the collection of peripheral leukocytes was done. Genomic
DNA was extracted, with a DNA extraction kit (IsoQuick; ORCA Research, Bothell, WA, USA), from peripheral leukocytes. Each exon of the TGFBI and M1S1 genes was amplified by polymerase chain reaction (PCR), using appropriate primers. PCR products were purified using the High Pure PCR Product Purification Kit (Roche Diagnostic, Mannheim, Germany), and directly sequenced with an automated sequencer (model 373A; Perkin Elmer Applied Biosystems, Foster City, CA, USA) in both sense and antisense strands, after termination reaction using a DNA sequencing kit (Dye Terminator Cycle Sequencing, Ready Reaction; Perkin Elmer Applied Biosystems). DNA was digested with restriction enzyme to verify mutation on the M1S1 gene. Nucleotide sequences for mutation analyses were compared with the nucleotide and deduced amino acid sequences of the TGFBI ( $\beta i g-h 3)$ human cDNA (Skonier et al. 1992) and the M1S1 gene (GA733) (Linnenbach et al. 1989), respectively. Corneas with each mutation were observed histopathologically.

\section{Results and discussion}

Autosomal dominant corneal dystrophies caused by mutation of the TGFBI (BIGH3) gene

In our study, seven different missense mutations were detected in the TGFBI gene in 154 patients from 118 families. No mutation was detected in 8 patients from four families with LCD or in the 50 normal volunteers. Table 2 shows the findings of our study including findings from Fujiki et al. (2000), and findings of studies at two widely separated institutions in Japan (Mashima et al. 2000). Codons R124 and R555 are hot spots in Japanese patients. The most frequent mutation in Japanese patients was R124H, which was found in $202(70.6 \%)$ of the 286 families in the studies shown in 
Table 2. Mutations of the $T G F B I$ gene associated with autosomal dominant corneal dystrophies

\begin{tabular}{|c|c|c|c|c|c|c|}
\hline \multirow[b]{2}{*}{ Clinical type } & & \multirow[b]{2}{*}{ Mutation } & \multicolumn{2}{|l|}{ Present study ${ }^{a}$} & \multirow{2}{*}{$\frac{\text { Mashima et al. } 2000}{\text { No. of families }}$} & \multirow{2}{*}{$\begin{array}{l}\text { Total no. of } \\
\text { families }(\%)\end{array}$} \\
\hline & & & No. of families & No. of patients & & \\
\hline \multirow{7}{*}{ Lattice CD } & Type I & $\mathrm{R} 124 \mathrm{C}$ & 13 & 25 & 23 & $36(12.6)$ \\
\hline & Atypical type I & L518P & $2^{b}$ & 6 & - & $2(0.7)$ \\
\hline & Type IIIA & P501T & $1^{\mathrm{c}}$ & $4^{c}$ & 10 & $11(3.8)$ \\
\hline & Type IV (late onset) & L527R & 9 & 9 & 1 & $10(3.5)$ \\
\hline & LCD (late onset) & N544S & - & - & 1 & $1(0.3)$ \\
\hline & Undetermined & & 4 & 8 & & $4(1.4)$ \\
\hline & Subtotal & & 29 & 52 & 35 & 63 \\
\hline Avellino CD & & $\mathrm{R} 124 \mathrm{H}$ & 84 & 99 & 118 & $202(70.6)$ \\
\hline Granular CD & & R555W & 5 & 5 & 7 & $12(4.2)$ \\
\hline \multirow{3}{*}{ Reis-Bücklers' CD } & Honeycomb-shaped & R555Q & 4 & 6 & 2 & $6(2.1)$ \\
\hline & Geographic & $\mathrm{R} 124 \mathrm{~L}$ & - & - & 2 & $2(0.7)$ \\
\hline & Subtotal & & 4 & 6 & 4 & 8 \\
\hline Total & & & 122 & 162 & 164 & $286(100)$ \\
\hline
\end{tabular}

${ }^{a}$ Including the findings from Fujiki et al. (2000)

${ }^{\mathrm{b}}$ One family and three patients were reported by Hirano et al. (2000)

${ }^{\mathrm{c}}$ This is a family with gelatinous drop-like CD. The four members are the proband with GDLD, his father, and the proband's two daughters. They are now aged 59, 85, 32, and 27 years, respectively. They have no symptoms of LCD IIIA; however, symptoms of LCD IIIA may appear in future because this disease has an onset age of 70-90 years (Yamamoto et al. 1998)

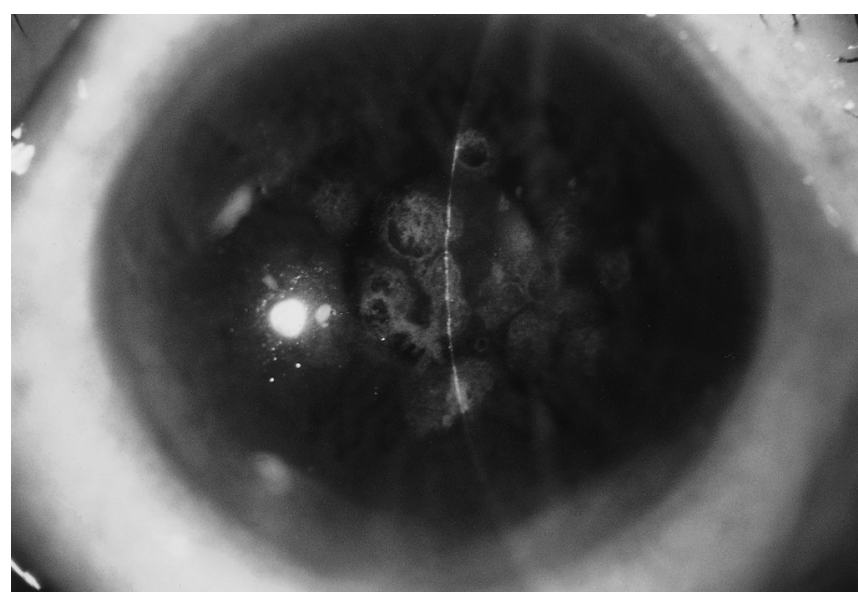

Fig. 1. Photograph of cornea of Avellino corneal dystrophy in patient with the R124H mutation in the TGFBI gene

Table 2. This disease is clinically classified as ACD, because it was identified in the Avellino district in Italy. GCD with the R555W mutation was detected in $12(4.2 \%)$ of the 286 families. ACD is a variant of GCD in which there are lattice deposits, in addition to the characteristic granular lesions. The most common appearance of the cornea in patients with the R124H mutation shows evidence of well circumscribed central stromal opacities, as seen in Fig. 1. Interestingly, ACD with the $\mathrm{R} 124 \mathrm{H}$ mutation is more common in Japanese patients than in Caucasians, and GCD with the R555W mutation, which is the classic form of GCD without lattice deposits, is rare in Japanese patients (Konishi et al. 1998; Fujiki et al. 2000). Homozygous R124H or R555W mutation of this gene has been reported (Mashima et al. 1997, 1998, and 2000; Fujiki et al. 1998a; Okada et al. 1998a and 1998c). The symptoms in all homozygous patients were more severe than those in heterozygous patients.
The R124C mutation was detected in 36 (12.6\%) of the 286 families together with our study, and Mashima et al. 2000. This is clinically LCD type I (LCDI), and is the second most common of the TGFBI gene mutations. The L518P, L527R, and N544S mutations were new mutations found in Japanese patients. The L518P mutation belongs to the category of LCDI (Endo et al. 1999; Hirano et al. 2000), the L527R mutation is LCD with deep stromal opacities and of late onset (Fujiki et al. 1998b) and the N544S mutation is also LCD of late onset. LCD with the L527R mutation has now been named LCD type IV (LCDIV) (Klintworth 1999). The P501T mutation, which causes LCD type IIIA (LCDIIIA), was found in Japanese patients (Yamamoto et al. 1998). In our study, four members of a family with GDLD were recorded. However, there were no symptoms of LCDIIIA, even in the 85-year-old father (Ha et al. 2000). Proband with GDLD has two kinds of mutations, homozygous Q118X of the M1S1 gene and heterozygous P501T of the TGFBI gene. The father and two daughters of the proband in our study have the heterozygous Q118X mutation of the M1S1 gene that is the carrier of GDLD, and the P501T mutation of the TGFBI gene. They have no symptoms of LCDIIIA, as shown by careful clinical checking. LCDIIIA with the P501T mutation has an onset age of 7090 years (Yamamoto et al. 1998). The proband, his father, and the proband's two daughters are now aged 50, 85, 32, and 27 years, respectively. Therefore, symptoms of LCDIIIA may appear in future. Interestingly, all four family members with the P501T mutation have the polymorphism $(\mathrm{C} \rightarrow \mathrm{T})$ at nucleotide position $1411-3$ of the $T G F B I$ gene, as has been reported in 11 other families with the P501T mutation (Tsujikawa et al. 2000a). Therefore, this family may be related to the other 11 families. It is highly possible that P501T is the founder mutation in Japanese, but this has not yet been confirmed. Although we found 
Table 3. Mutations of the M1S1 gene associated with gelatinous drop-like corneal dystrophy

\begin{tabular}{lllll}
\hline & \multicolumn{2}{c}{ Tsujikawa et al. 2000 } & & \multicolumn{2}{c}{ Present study } & \\
\cline { 2 - 2 } Genotype & No. of families & & No. of families & Total no. of families \\
\hline Q118X/Q118X & 31 & 7 & 38 \\
Q118X/632delA & 1 & & 1 \\
632delA/632delA & 1 & & 1 \\
Q207X/Q207X & 1 & & 1 \\
S170X/S170X & 1 & 1 & 1 \\
Undetermined & & 8 & 43 \\
\hline
\end{tabular}

only the R555Q mutation, which is characterized by honeycomb-shaped opacities, in 6 patients from 4 families with RBCD in our study, the R124L mutation has been reported in RBCD patients (Okada et al. 1998b; Mashima et al. 2000).

Autosomal recessive gelatinous drop-like corneal dystrophy caused by mutation of the M1S1 gene

Tsujikawa et al. (1999) cloned the gene responsible for GDLD and detected four deleterious mutations (Q118X, 632delA, Q207X, and S170X) in the M1S1 gene, encoding a gastrointestinal tumor-associated antigen. The Q118X mutation was the most common in the GDLD patients, occurring in 77 (91.7\%) of the 84 mutated alleles (Table 3). Haplotype analyses using nearby polymorphic markers of the M1S1 gene in the patients indicated that the Q118X mutation is a Japanese founder mutation and reflects linkage disequilibrium alleles (Tsujikawa et al. 1999 and 2000b). Thus, most patients are Japanese, with few reported cases in other countries. In our study, the homozygous Q118X mutation of the M1S1 gene was detected in nine patients from seven of eight families with GDLD, and the parents of the probands in four families were consanguineous. Parents and unaffected relatives were found to be heterozygous for this mutation. Our results also supported the findings that the Q118X mutation was a founder mutation. No mutation in the coding region of the M1S1 gene was detected in one family with GDLD. However, the patient in this family was diagnosed clinically as having GDLD, and histopathological findings showed amyloid deposits in Bowman's membrane and the anterior stromal layer. We examined the promoter region in the M1S1 gene in this family and found no changes. Although anomalies of the $3^{\prime}$ untranslated region should be considered (Conne et al. 2000), there may be anomalies in other genes that are causative for GDLD.

\section{Conclusion}

The two CDs (i.e., autosomal dominant and autosomal recessive CDs) with different modes of inheritance, with different causative genes, TGFBI and M1S1, show deposits in the stroma. Although the type of mutation is manifested by different histopathological findings, most patients with LCD, ACD, and GDLD showed amyloid deposits in several parts of the subepithelial layer and/or stromal layer. However, amyloid deposits were not observed in GCDGI, which in the classic form of GCD, or in RBCD, in which there are honeycomb-shaped opacities, despite GCDGI and RBCD being caused by a mutation of the same gene, TGFBI.

Immunolocalization of $\beta$ ig-h3 protein was strongest in Bowman's layer, then along the stromal interlamellar area and at the sites of attachment of collagen to Descemet's membrane (Streeten et al. 1999). The mechanisms responsible for the occurrence of the diseases and for the appearance of the differing deposits are still not known; however, the variability of form may be related to different aminoacid substitutions at different nucleotide positions, and regional interactions of the protein.

Our studies have shown that codons R124 and R555 of the TGFBI gene in autosomal dominant CDs are hotspots in Japanese patients, as they are in other ethnic groups, as reported previously (Korvatska et al. 1998). The most common alteration of the TGFBI gene in Japanese patients is $\mathrm{ACD}$, with the R124H mutation, while the second most common is LCDI, with the R124C mutation.

For autosomal recessive GDLD caused by mutation of the M1S1 gene, 38 families were homozygous for the Q118X mutation. This suggests a specific founder mutation arising from a common ancestor, as already reported (Tsujikawa et al. 2000b).

Histopathological findings were consistent with differences in the positions and/or kinds of deposits, depending on the type of the mutation. Although ACD, LCD, and GDLD show amyloid deposits in specific parts of the stroma, GCD with the R555W mutation, and honeycombshaped RBCD with the R555Q mutation, showed absence of these amyloid deposits. These results show a clear genotype/phenotype correlation in genetic corneal dystrophies caused by the TGFBI gene.

Acknowledgments The authors thank Dr. Masao Nagata, Department of Ophthalmology, Tottori University, Faculty of Medicine, for support given to our study. Professor Yoshihiro Hotta, Hamamatsu University School of Medicine; Dr. Tatsuo Yamaguchi, St. Luke's International Hospital; Drs. Nobuo Ishida and Shinichiro Endo, Ishida Eye Hospital; Drs. Nguyen T. Ha, Toshiyuki Yokoyama, Toshiyuki 
Takano, Yuko Uesugi, Takuji Kato, and Fumio Lo, and Ms. Misako Takeda, Mr. Jingo Araki, and Mr. Yasuo Watanabe, Department of Ophthalmology, Juntendo University School of Medicine, are coworkers in the laboratory. The authors also thank Professor Marilou G. Nicolas, Dean of the College of Arts and Sciences, University of the Philippines, Manila, for editing this manuscript. Part of this review was presented at The Millennium Meeting of Eye MDs, 10th PhilippineJapan Joint Meeting in Ophthalmology, November 27-29, 2000, Manila, the Philippines.

\section{References}

Conne B, Stutz A, Vassalli JD (2000) The 3' untranslated region of messenger RNA: a molecular "hotspot" for pathology? Nat Med 6:637-641

Endo S, Ha NT, Fujiki K, Hotta Y, Nakayasu K, Yamaguchi T, Ishida N, Kanai A (1999) Leu518Pro mutation of the $\beta i g-h 3$ gene causes lattice corneal dystrophy type I. Am J Ophthalmol 128:104-106

Fujiki K, Hotta Y, Nakayasu K, Kanai A (1998a) Homozygotic patient with $\beta i g-h 3$ gene mutation in granular dystrophy. Cornea 17:288-292

Fujiki K, Hotta Y, Nakayasu K, Yokoyama T, Takano T, Yamaguchi T, Kanai A (1998b) A new L527R mutation of the $\beta I G H 3$ gene in patients with lattice corneal dystrophy with deep stromal opacities. Hum Genet 103:286-289

Fujiki K, Hotta Y, Nakaysasu K, Yamaguchi T, Kato T, Uesugi Y, Ha NT, Endo S, Ishida N, Lu W-N, Kanai A (2000) Six different mutations of TGFBI ( $\beta$ ig- $h 3$, keratoepithelin) gene found in Japanese corneal dystrophies. Cornea 19:842-845

Ha NT, Fujiki K, Hotta Y, Nakayasu K, Kanai A (2000) Q118X mutation of M1S1 gene caused gelatinous drop-like corneal dystrophy: the P501T of BIGH3 gene found in a family with gelatinous droplike corneal dystrophy. Am J Ophthalmol 130:119-120

Hayakawa M, Fujiki K, Kanai A, Matsumura M, Honda Y, Sakaue H, Tamai M, Sakuma T, Tokoro T, Yura T, Kubota N, Kawano S, Matsui M, Yuzawa M, Oguchi Y, Akeo K, Adachi E, Kimura T, Miyake Y, Horiguchi M, Wakabayashi K, Ishizaka N, Koizumi K, Uyama M, Tagami N, Ishibashi T, Honda T, Nakagawa T, Takeda M, Choshi K, Watanabe M, Tamura O, Shimowake N, Ueno H, Yoshida K, Isashiki Y, Ohba N (1997) Multicenter genetic study of retinitis pigmentosa in Japan: II. Prevalence of autosomal recessive retinitis pigmentosa. Jpn J Ophthalmol 41:7-11

Hirano K, Hotta Y, Fujiki K, Kanai A (2000) Corneal amyloidosis caused by Leu518Pro mutation of $\beta i g-h 3$ gene. Br J Ophthalmol 84:583-585

Hosoda Y, Fujiki K, Nakajima A (1983) A research of consanguinity in Japanese young couples. Jpn J Hum Genet 28:205-207

Hotta Y, Fujiki K, Ono K, Fujimaki T, Nakayasu K, Yamaguchi T, Kanai A (1998) Arg124Cys mutation of the $\beta i g-h 3$ gene in a Japanese family with lattice corneal dystrophy type I. Jpn J Ophthalmol 42:450-455

Imaizumi Y (1986) A recent survey of consanguineous marriages in Japan. Clin Genet 30:230-233

Kawano H, Fujiki K, Kanai A (1992) Prevalence of gelatinous droplike corneal dystrophy in Japan (in Japanese). Atarashii Ganka (J Eye) 9:1879-1882

Klintworth GK (1999) Advances in the molecular genetics of corneal dystrophies. Am J Ophthalmol 128:747-754

Konishi M, Mashima Y, Yamada M, Kudoh J, Shimizu N (1998) The classic form of granular corneal dystrophy associated with R555W mutation in the BIGH3 gene is rare in Japanese patients. Am J Ophthalmol 126:450-452

Konishi M, Yamada M, Nakamura Y, Mashima Y (1999) Varied appearance of cornea of patients with corneal dystrophy associated with R124H mutation in the BIGH3 gene. Cornea 18:424-429

Korvatska E, Munier FL, Djemaï A, Wang MX, Frueh B, Chiou AG, Uffer S, Ballesrazzi E, Braunstein RE, Forster RK, Culbertson WW, Boman H, Zografos L, Schorderet DF (1998) Mutation hot spots in 5q31-linked corneal dystrophies. Am J Hum Genet 62:320-324

Linnenbach AJ, Wojcierowski J, Wu S, Pyrc JJ, Ross AH, Dietzschold B, Speicher D, Koprowski H (1989) Sequence investigation of the major gastrointestinal tumor-associated antigen gene family, GA733. Proc Natl Acad Sci USA 86:27-31

Mashima Y, Imamura Y, Konishi M, Nagasawa A, Yamada M, Oguchi Y, Kudoh J, Shimizu N (1997) Homogeneity of kerato-epithelin codon 124 mutations in Japanese patients with either of two types of corneal stromal dystrophy. Am J Hum Genet 61:1448-1450

Mashima Y, Konishi M, Nakamura Y, Imamura Y, Yamada M, Ogata T, Kudoh J, Shimizu N (1998) Severe form of juvenile corneal stromal dystrophy with homozygous $\mathrm{R} 124 \mathrm{H}$ mutation in the keratoepithelin gene in five Japanese patients. $\mathrm{Br} \mathrm{J}$ Ophthalmol 82:1280-1284

Mashima Y, Yamamoto S, Inoue Y, Yamada M, Konishi M, Watanabe H, Maeda N, Shimomura Y, Kinoshita S (2000) Association of autosomal dominantly inherited corneal dystrophies with $B I G H 3$ gene mutations in Japan. Am J Ophthalmol 130:516-517

Munier FL, Korvatska E, Djemaï A, Le Paslier D, Zografos L, Pescia G, Schorderet DF (1997) Kerato-epithelin mutations in four 5q31linked corneal dystrophies. Nat Genet 15:247-251

Nakaizumi G (1914) A rare case of corneal dystrophy (in Japanese). J Jpn Ophthalmol Soc 18:949-950

Okada M, Yamamoto S, Watanabe H, Inoue Y, Tsujikawa M, Maeda N, Shimomura Y, Nishida K, Kinoshita S, Tano Y (1998a) Granular corneal dystrophy with homozygous mutations in the keratoepithelin gene. Am J Ophthalmol 126:169-176

Okada M, Yamamoto S, Tsujikawa M, Watanabe H, Inoue Y, Maeda N, Shimomura Y, Nishida K, Quantock AJ, Kinoshita S, Tano Y (1998b) Two distinct kerato-epithelin mutations in Reis-Bücklers corneal dystrophy. Am J Ophthalmol 126:535-542

Okada M, Yamamoto S, Inoue Y, Watanabe H, Maeda N, Shimomura Y, Ishii Y, Tano Y (1998c) Severe corneal dystrophy phenotype caused by homozygous R124H keratoepithelin mutations. Invest Ophthalmol Vis Sci 39:1947-1953

Saito T (1985) An expected decrease in incidence of Wilson's disease due to decrease in consanguinity. Jpn J Human Genet 30:249253

Saito T (1988) An expected decrease in the incidence of autosomal recessive disease due to decreasing consanguineous marriages. Genet Epidemiol 5:421-432

Skonier J, Neubauer M, Madisen L, Bennett K, Plowman GD, Purchio AF (1992) cDNA cloning and sequence analysis of $\beta i g-h 3$, a novel gene induced in a human adenocarcinoma cell line after treatment with transforming growth factor- $\beta$. DNA Cell Biol 11:511-522

Small KW, Mullen L, Barletta J, Graham K, Glasgow B, Stern G, Yee R (1996) Mapping of Reis-Bücklers' corneal dystrophy to chromosome 5q. Am J Ophthalmol 121:384-390

Stone EM, Mathers WD, Rosenwasser GOD, Holland EJ, Folberg R, Krachmer JH, Nichols BE, Gorevic PD, Taylor CM, Streb LM, Fishbaugh JA, Daley TE, Sucheski BM, Sheffield VC (1994) Three autosomal dominant corneal dystrophies map to chromosome $5 \mathrm{q}$. Nat Genet 6:47-51

Streeten BW, Qi Y, Klintworth GK, Eagle RC, Strauss JA, Bennett K (1999) Immunolocalization of $\beta$ ig-h3 protein in 5q31-linked corneal dystrophies and normal corneas. Arch Ophthalmol 117:67-75

Tsujikawa M, Kurahashi H, Tanaka T, Okada M, Yamamoto S, Maeda N, Watanabe H, Inoue Y, Kiridoshi A, Matsumoto K, Ohashi Y, Kinoshita S, Shimomura Y, Nakamura Y, Tano Y (1998) Homozygosity mapping of a gene responsible for gelatinous drop-like corneal dystrophy to chromosome 1p. Am J Hum Genet 63:1073-1077

Tsujikawa M, Kurahashi H, Tanaka T, Nishida K, Shimomura Y, Tano Y, Nakamura Y (1999) Identification of the gene responsible for gelatinous drop-like corneal dystrophy. Nat Genet 21:420-423

Tsujikawa K, Tsujikawa M, Inoue Y, Maeda N, Watanabe H, Fujikado N, Tano Y (2000a) Founder effect found in Japanese lattice corneal dystrophy Type IIIA (in Japanese). The 24th Corneal Conference, February 17-19, 2000, Chiba, Japan. Abstract, pp 69

Tsujikawa M, Tsujikawa K, Maeda N, Watanabe H, Inoue Y, Mashima Y, Shimomura Y, Tano Y (2000b) Rapid detection of M1S1 mutations by the protein truncation test. Invest Ophthalmol Vis Sci 41:2466-2468

Yamamoto S, Okada M, Tsujikawa M, Shimomura Y, Nishida K, Inoue $\mathrm{Y}$, Watanabe $\mathrm{H}$, Maeda $\mathrm{N}$, Kurahashi $\mathrm{H}$, Kinoshita S, Nakamura Y, Tano Y (1998) A kerato-epithelin ( $\beta$ ig-h3) mutation in lattice corneal dystrophy type IIIA. Am J Hum Genet 62:719722 